\title{
Venous thromboprophylaxis risk assessment amongst gynaecological patients in a tertiary health institution, south west Nigeria
}

\author{
Ogunlaja Olumuyiwa Ayotunde, ${ }^{1}$ Abolarin Ademola, ${ }^{2}$ Ogunlaja Idowu Pauline, ${ }^{3}$ \\ Aworinde Olufemi, ${ }^{1}$ Olasinde Yetunde, ${ }^{4}$ Akinola Samuel, ${ }^{1}$ Bojuwoye Matthew Olumuyiwa ${ }^{5}$ \\ ${ }^{1}$ Department Of Obstetrics and Gynaecology; ${ }^{2}$ Department Of Haematology, Bowen University Teaching \\ Hospital, Ogbomoso, Oyo state; ${ }^{3}$ Department Of Obstetrics and Gynaecology, General Hospital, Ilorin, \\ Kwara State; ${ }^{4}$ Department of Paediatrics, Bowen University Teaching Hospital, Ogbomoso, Oyo state; \\ ${ }^{5}$ Department Of Medicine, University of Ilorin Teaching Hospital, Ilorin, Kwara state
}

\begin{abstract}
Venous Thromboembolism (VTE), is a major health concern that has continued to pose a challenge to clinicians. It is a major cause of morbidity and mortality in our environment. In recent years there has been renewed attention on the need for thromboprophylaxis to prevent VTE and its consequences. This is a prospective study carried out on the gynaecological in patients of Bowen University Teaching Hospital, Ogbomoso. This study involved the use of a questionnaire with the details of the Caprini score in assessing patients. Our study revealed that $83(58.5 \%)$ patients had low risk for VTE while 55 (38.7\%) had moderate risk for VTE. Only 4 (2.8\%) of participants had a high risk for VTE and none of the gynaecological patients could be classified as very low risk according to the Caprini index. There is a need to train and retrain health care givers on the importance of thromboprophylaxis. This training should include the development of local protocols similar to international guidelines meeting the local needs, this will go a long way to ensure it is user friendly to healthcare workers.
\end{abstract}

Correspondence: Olumuyiwa A Ogunlaja, Department of Obstetrics and Gynaecology, Bowen University Teaching Hospital, Ogbomoso, Oyo state.

Tel.: +2348052273290

E-mail: lajamuyiwa@yahoo.com

Key words: Venous thromboembolism; deep venous thrombosis; pulmonary embolism; risk assessment.

Ethics approval and consent to participate: Ethics approval was sought and obtained before the commencement of the study from the Research and Ethics Committee of Bowen University Teaching Hospital, Ogbomoso, Oyo State. Written informed consent was obtained from all participants in the study.

Received for publication: 6 August 2020.

Revision received: 31 August 2020.

Accepted for publication: 15 September 2020.

This work is licensed under a Creative Commons Attribution NonCommercial 4.0 License (CC BY-NC 4.0).

(C) Copyright: the Author(s),2020

Licensee PAGEPress, Italy

Annals of Clinical and Biomedical Research 2020; 1:88

doi:10.4081/acbr.2020.88

\section{Introduction}

Venous Thromboembolism (VTE), is a major health concern that has continued to pose a challenge to clinicians. It is a major cause of morbidity and mortality in our environment. ${ }^{1,2}$

In recent years there has been renewed attention on the need for thromboprophylaxis to prevent VTE and its consequences.

VTE encompasses deep venous thrombosis (DVT) and pulmonary embolism (PE). Many patients are usually without symptoms hence it can be regarded as a silent killer. ${ }^{3,4}$

The goal of thromboprophylaxis is to prevent the morbidity and mortality associated with VTE. This is done using either pharmacological agents or mechanical devices. The common pharmacological agents include unfractionated heparin, Low Molecular Weight Heparin (LMWH) and warfarin, while the mechanical means include Graduated Compression Stockings (GCS), Intermittent Pneumatic Compression (IPC) and venous foot pump. ${ }^{5}$ Research work done in the past have proven that hospital acquired VTE can be prevented by effective thromboprophylaxis practices. $^{6}$

Consequently, a prompt and a proactive approach is regarded as cheap and life saving.

In carrying out this proactive approach, patients can be identified by common risk factors for VTE which include: age greater 40 years, immobility, obesity, prolonged medical or post-surgical conditions either in the past or present, malignancy, trauma, indwelling intravenous devices and paresis to mention a few. All these factors confer the patients with varying degree of risk to VTE. ${ }^{7}$ In this study we highlighted the various risk factors based on the Caprini scoring index to ascertain the VTE risk assessment score in the gynaecological patients admitted on in our hospital.

\section{Objectives}

To access the individual risk factors associated with the development of VTE among gynaecological in-patients managed at Bowen University Teaching Hospital, Ogbomoso. To calculate the Caprini score and assess VTE risk among gynaecological patients in Bowen University Teaching Hospital, Ogbomoso.

\section{Materials and Methods}

This prospective study was carried out on the gynaecological in patients of Bowen University Teaching Hospital, Ogbomoso between January and June 2019.

A nonprobability sampling technique was used with a purposive approach towards identifying gynaecological patients since they are the category of research interest. 
Sample size was calculated using a previous study in Africa which showed the prevalence of VTE to be between $2.4 \%$ to $9.6 \%{ }^{8}$

Hence, sample size calculation:

$\mathrm{n}=(1.96)^{2} \mathrm{p}(1-\mathrm{q}) /(0.05)^{2}$

Minimum sample size calculation $=(1.96)^{2} \times 0.096(1-0.096) /(0.05)^{2}$ Minimum sample size $=133.4$

Written informed consent was obtained from all participants in the study, the questionnaire was administered by research assistants to all consenting in- patients in the gynaecological ward of Bowen University Teaching Hospital, Ogbomoso. Participation was voluntary and patients were free to withdraw at any stage of the study. This study involved the use of a questionnaire with the details of the Caprini score in assessing patients.

\section{Ethics approval}

Ethics approval was sought and obtained before the commencement of the study from the Research and Ethics Committee of Bowen University Teaching Hospital, Ogbomoso, Oyo State.

\section{Venous Thrombosis risk assessment}

The VTE risk factor assessment tool by Caprini et al. was used to assess risk for VTEamong respondents. The Caprini score is used to assess Surgical patients for VTE risk. Points are awarded for each risk factor present in the patient, and a total score is generated.

Patient related factors that increase risk include Age $>60$ years, past history of VTE, Immobility before surgery Cancer, pregnancy and inherited thrombophilia. Procedure related factors include, duration of procedure, degree of immobility and tissue damage. These factors are gotten from the questionnaire and patient records. ${ }^{1}$

A total score of 0-2 is classified as very low risk for VTE, 3-4 and 5-8 as moderate and high risk respectively, while a score of $>$ 8 is classified as very high risk for VTE. ${ }^{1}$

\section{Results}

A total of one hundred and forty two (142) women were involved in this study, with age ranging from 15 to 65 years. Table 1 , shows the age distribution and some biometric variable of the patients involved in the study like age, weight, and height. The weight and height are of particularly importance in determining the body mass index which is also another important factor in accessing the risk of VTE.

Tables 2 to 6 shows the frequency of the various risk factors for venous thromboembolism. These risk factors includes- age, planned minor surgery, major surgery, varicose veins, history of inflammatory bowel disease, swollen legs, obesity, history of congestive cardiac failure in less than one month, history of sepsis in less than one month, serious lung disease in less than on month, abnormal pulmonary function, medical patient on bed rest, use of leg cast or brace, blood transfusion in less than one month, use of oral contraception, history of repeated miscarriages, history of medical disorders like stroke, previous malignancy or chemotherapy treatment, and previous or family history of coagulation disorders. Some of the above risk factors have been stratified based on the severity of it perceived risk of contribution to venous thromboembolism.
Table 7 is a summary of the risk assessment of the participants in the study. Our study revealed that $83(58.5 \%)$ patients had low risk for VTE while $55(38.7 \%)$ had moderate risk for venous thromboembolism. Only 4 (2.8\%) of participants had a high risk for VTE and none of the gynaecological patients could be classified as very low risk according to the Caprini index.

Table 1. Age and biometric parameters.

\begin{tabular}{lccl} 
Variable & Frequency & Percentage \\
Age (years) & $15-35$ & 31 & 21.8 \\
& $26-35$ & 77 & 54.2 \\
& $36-45$ & 26 & 18.3 \\
& $46-55$ & 3 & 2.1 \\
Weight (Kg) & $56-65$ & 5 & 3.5 \\
& $35-45$ & 2 & 1.4 \\
& $46-55$ & 15 & 10.6 \\
& $56-65$ & 49 & 34.5 \\
& $66-75$ & 25 & 17.6 \\
& $76-85$ & 37 & 26.1 \\
& $86-95$ & 9 & 6.3 \\
& $96-105$ & 4 & 2.8 \\
& $106-115$ & 1 & .7 \\
\hline Height (m) & $140-150$ & 2 & 1.4 \\
& $151-160$ & 87 & 61.3 \\
& $161-170$ & 47 & 33.1 \\
& $171-180$ & 6 & 4.2 \\
\hline Total & 142 & 100.0 \\
\hline
\end{tabular}

Table 2. Venous thromboembolism risk factor indices.

\begin{tabular}{lccc} 
Variable & & Frequency & Percentage \\
Age 40-59 years & Yes & 7 & 4.9 \\
& No & 135 & 95.1 \\
Minor surgery planned & Yes & 6 & 4.2 \\
& No & 136 & 95.8 \\
\hline History of major surgery & Yes & 25 & 17.6 \\
& No & 117 & 82.4 \\
Varicose veins & Yes & 0 & 0 \\
& No & 142 & 100 \\
\hline History of inflammatory bowel disease & Yes & 10 & 7.0 \\
Swollen legs (current) & No & 132 & 93.0 \\
Obesity, Body Mass Index (BMI) $>30$ & Yes & 66 & 46.5 \\
& No & 76 & 53.5 \\
\hline Congestive heart failure (<1 month) & Yes & 3 & 2.1 \\
Sepsis (<1 month) & No & 139 & 97.9 \\
Serious lung disease including & Yes & 0 & 0 \\
Pneumonia (<1 month) & No & 142 & 100 \\
\hline Abnormal pulmonary function & Yes & 1 & 0.7 \\
& No & 141 & 99.3 \\
Medical patient currently at bed rest & Yes & 8 & 5.6 \\
& No & 134 & 94.4 \\
\hline Leg plaster cast or brace & Yes & 1 & 0.7 \\
& No & 141 & 99.3 \\
Other risk factor & Yes & 0 & 0 \\
& No & 142 & 100 \\
\hline Blood transfusion (<1 month) & Yes & 0 & 0 \\
& No & 142 & 100 \\
\hline
\end{tabular}

For each risk factor mentioned above the patient scores 1 . 


\section{Discussion}

VTE is a major cause of morbidity and mortality, hence the need for thromboprophylaxis by either the use of pharmacological agents or mechanical devices. However, for optimal patient care there is the need to follow the international guidelines in the management of VTE, this has been largely lacking in the management of patients due to lack of use by many care givers. ${ }^{8}$

The majority (97.2\%) of the patients had either low or moderate risk for VTE. High risk for VTE was found in $2.8 \%$ of the patients. The implication of this is that none of gynaecological patients admitted in the period under review had a very low risk for venous thromboembolism (Table 7), these emphasizes the need for gynaecologist to be proactive in the risk assessment of VTE in order to avert its adverse consequences

The above finding shows the potential magnitude of problem associated with venous thromboembolism. A retrospective study on post mortem patients also shows that VTE can be said to be a significant cause of patient morbidity and mortality. ${ }^{2}$

Studies in predominantly black populations in the UK have shown that younger blacks present with VTE than whites and they have more proximal events compared to whites. ${ }^{11,12}$ The implication of this further justifies the importance for routine risk assessment for thromboprophylaxis amongst patients.

Knowledge about VTE varies from one physician to the other, likewise from one health facility to another. ${ }^{13,14}$ It is important to note that when these risk assessments were made the patients did not benefit from these pharmacological agents or mechanical devices but were only encouraged to ambulate early especially in post-operative patients. The reasons for this vary from lack of physician prescription probably due to paucity of information on

Table 3. Venous thromboembolism risk factor indices.

\begin{tabular}{|c|c|c|c|}
\hline Variable & & Frequency & Percentage \\
\hline $\begin{array}{l}\text { Oral contraceptives or hormone } \\
\text { replacement therapy }\end{array}$ & $\begin{array}{l}\text { Yes } \\
\text { Yes }\end{array}$ & $\begin{array}{c}13 \\
129\end{array}$ & $\begin{array}{c}9.2 \\
90.8\end{array}$ \\
\hline Pregnancy or postpartum (<1 month) & $\begin{array}{l}\text { Yes } \\
\text { No }\end{array}$ & $\begin{array}{c}11 \\
131\end{array}$ & $\begin{array}{l}7.7 \\
92.3 \\
\end{array}$ \\
\hline $\begin{array}{l}\text { History of unexplained stillborn infant, } \\
\text { recurrent spontaneous abortion }(\geq 3) \text {, } \\
\text { premature birth with toxaemia or growth } \\
\text { restricted infant }\end{array}$ & $\begin{array}{l}\text { Yes } \\
\text { No }\end{array}$ & $\begin{array}{c}115 \\
27\end{array}$ & $\begin{array}{l}81.0 \\
19.0\end{array}$ \\
\hline  & Total & 142 & 100.0 \\
\hline
\end{tabular}

Table 4. Venous thromboembolism risk factor indices.

\begin{tabular}{|c|c|c|c|}
\hline Variable & & Frequency & Percentage \\
\hline Age 61 - 74 years & $\begin{array}{l}\text { Yes } \\
\text { No }\end{array}$ & $\begin{array}{c}6 \\
136\end{array}$ & $\begin{array}{c}4.2 \\
95.8\end{array}$ \\
\hline Major surgery (>60 minutes) & $\begin{array}{l}\text { Yes } \\
\text { No }\end{array}$ & $\begin{array}{c}3 \\
139\end{array}$ & $\begin{array}{c}2.1 \\
97.9\end{array}$ \\
\hline Arthroscopic surgery ( $>60$ minutes) & $\begin{array}{l}\text { Yes } \\
\text { No }\end{array}$ & $\begin{array}{c}23 \\
119\end{array}$ & $\begin{array}{l}16.2 \\
83.8\end{array}$ \\
\hline Laparoscopic (>60 minutes) & $\begin{array}{l}\text { Yes } \\
\text { No }\end{array}$ & $\begin{array}{c}0 \\
142\end{array}$ & $\begin{array}{c}0 \\
100.0\end{array}$ \\
\hline Previous malignancy & $\begin{array}{l}\text { Yes } \\
\text { No }\end{array}$ & $\begin{array}{c}0 \\
142\end{array}$ & $\begin{array}{c}0 \\
100.0\end{array}$ \\
\hline Morbid obesity (BMI > 40) & $\begin{array}{l}\text { Yes } \\
\text { No }\end{array}$ & $\begin{array}{c}1 \\
141\end{array}$ & $\begin{array}{c}0.7 \\
99.3\end{array}$ \\
\hline
\end{tabular}

For each risk factor mentioned above the patient scores 2.
VTE risk assessment or financial constraint on the part of patients to procure these medications when prescribed. A similar observation was made in a previous study. ${ }^{13,14}$

Unlike previous research work our study focused on the use of

Table 5. Venous thromboembolism risk factor indices.

\begin{tabular}{lccc} 
Variable & & Frequency & Percentage \\
Age 75 years or more & Yes & 1 & 0.7 \\
& No & 140 & 98.6 \\
Major surgery lasting 2-3 hours & Yes & 1 & 0.7 \\
& No & 141 & 99.3 \\
\hline BMI $>50$ & Yes & 2 & 1.4 \\
& No & 140 & 98.6 \\
History of SVT, DVT/PE & Yes & 0 & 0 \\
& No & 142 & 100.0 \\
\hline Family history of DVT/PE & No & 142 & 100.0 \\
& Yes & 0 & 0 \\
Present cancer or chemotherapy & No & 142 & 100.0 \\
\hline Positive factor V Leiden & Yes & 2 & 1.4 \\
& No & 140 & 98.6 \\
Positive prothrombin 20210A & No & 142 & 100.0 \\
& Yes & 0 & 0 \\
\hline Elevated serum homocysteine & No & 142 & 100.0 \\
& Yes & 0 & 0 \\
Positive lupus anticoagulant & No & 142 & 100.0 \\
& Yes & 0 & 0 \\
\hline Elevated anticardiolipin antibodies & No & 142 & 100.0 \\
& Yes & 0 & 0 \\
Heparin induced thrombocytopenia & No & 142 & 100.0 \\
& Yes & 0 & 0 \\
\hline Other thrombophilia & No & 142 & 100.0 \\
Type & Yes & 0 & 0 \\
& No & 142 & 100.0 \\
& Yes & 0 & 0 \\
\hline & & & \\
& & & \\
& & &
\end{tabular}

For each risk factor mentioned above the patient scores 3.

Table 6. Venous thromboembolism risk factor indices.

\begin{tabular}{lccc} 
Variable & & Frequency & Percentage \\
Elective major lower extremity & No & 142 & 100.0 \\
arthroplasty & Yes & 0 & 0 \\
Hip, pelvis or leg fracture (<1 month) & No & 142 & 100.0 \\
& Yes & 0 & 0 \\
\hline Stroke (<1 month) & No & 142 & 100.0 \\
& Yes & 0 & 0 \\
Multiple trauma (<1 month) & No & 142 & 100.0 \\
& Yes & 0 & 0 \\
\hline Acute spinal cord injury (Paralysis) & No & 142 & 100.0 \\
(<1 month) & Yes & 0 & 0 \\
Major surgery lasting over 3 hours & No & 142 & 100.0 \\
& Yes & 0 & 0 \\
\hline
\end{tabular}

For each risk factor mentioned above the patient scores 5.

Table 7. Total risk score classification.

Very low risk (0-

Low risk (3-4)

Moderate risk (5-8)

58.5

High risk $(>8)$

$\begin{array}{cc}83 & 58.5 \\ 55 & 38.7 \\ 4 & 2.8\end{array}$


only one tool: the Caprini scoring index in VTE risk assessment. ${ }^{15}$ Nevertheless, in the previous research work the various scoring indices were found to be similar in prognosticating the risk for VTE risk assessment. ${ }^{15}$ However, our research work revealed only a minority $(2.8 \%)$ of our patients had high risk for VTE, however, a similar research in the past revealed that majority of the obstetrics and gynaecology patient had a high risk for developing VTE.

It is imperative to state that most of the clinical features of VTE are nonspecific. ${ }^{16,17}$ These clinical features depends on the location of the affected vessel and the extent of occlusion of the vessel. Both DVT and PE may be asymptomatic, and up to $50 \%$ of DVT patients have been reported to be asymptomatic; consequently, a high index of suspicion is always expected on the part of the clinician.

Hence, there is a need to train and retrain health care givers on the importance of thromboprophylaxis. This training should include the development of local protocols similar to current international guidelines but with peculiarities of our local needs and society. ${ }^{1}$ Achieving this will improve its use by healthcare workers thereby ensuring a robust and better approach to quality healthcare delivery, health promotion and preventing the sequelae that may be associated with VTE if left untreated or not identified early.

\section{References}

1. Awodu OA, Shokunbi WA, Akanmu AS, et al. Guideline for management of Venous thromboembolism in Nigeria. Technical Report. A publication of the Nigerian Society for Haematology and Blood Transfusion 2018

2. Sotumbi PT, Idowu AT, Akang EE, Aken'Ova YA. Prevalence of venous thromboembolism at post-mortem in an African population: a cause for concern. Afr J Med Sci 2006;35:345-8.

3. Ekwere TA, Ino-Ekanem BM, Ekanem A. Venous thromboembolism: awareness and practice of thromboprophylaxis among physicians in a tertiary-care hospital. Int J Med Biomed Res 2015;4.

4. Blann AD, Lip GYH. Venous thromboembolism. Br Med J 2006;332:215-9.
5. Cayley jr WE. Preventing deep venous thrombosis in hospital in-patients. BMJ 2007;335:147-51.

6. Cohen AT, Davidson BL, Gallas AS, et al. ARTEMIS Investigators. Efficacy and safety of fondaparinux for the prevention of venous thromboembolism in older acute medical patients: randomised placebo controlled trial. BMJ 2006;332:325-9.

7. Caprini JA. Thrombosis risk assessment as a guide to quality patient care. Dis Mon 2005;51:70-8.

8. Danwang C, Temgoua MN, Agbor VN, et al. Epidemiology of venous thromboembolism in Africa: a systematic review. J Thromb Haemost 2017;15:1770-81.

9. Cohen AT, Tapson VF, Bergmann JF, et al. Venous thromboembolism, risk and prophylaxis in the acute hospital care setting (ENDORSE study): A multinational cross-sectional study. Lancet 2008;371:387-94.

10. Kahn SR, Panju A, Greets W, et al. Multicenter evaluation of the use of venous thromboembolism prophylaxis in acutely ill medical patients in Canada. Thromb Res 2007;119:145-55.

11. Roberts LN, Patel RK, Arya R. Venous thromboembolism and ethnicity. Br J Haematol 2009;146:369-83.

12. Patel RK, Roopen A. Venous thromboembolism: racial and ethnic influences. Therapy 2008;5:169-75.

13. Gao F, Kause J. Thromboprophylaxis awareness among hospital staff. Br J Nurs 2010;19:1175-8.

14. Majluf-Cruz A, Castro Martinez G, Herrera Cornejo MA, et al. Awareness regarding venous thromboembolism among internal medicine practitioners in Mexico. A national cross-sectional study. Intern Med J 2012;42:1335-41.

15. Olufemi-Aworinde KJ, Aworinde OO, Olutogun TA, et al. Predictive value of venous thromboembolism risk assessment scoring tools among surgical patients. Eur J Biomed Pharm Sci 2018;5:88-91.

16. Narani KK. Deep vein thrombosis and pulmonary embolism Prevention, management, and anaesthetic considerations. Indian J Anaesth 2010;54:8-17.

17. Kaushansky K, Lichtman M, Beutler E, et al. Williams Hematology, Eighth Edition. 8 edition. New York: McGrawHill Education/Medical; 2010. 